\title{
Nitric Oxide as an Efferent Modulator of Circadian Pacemaker Neurones in the Eye of the Marine Mollusc Bulla gouldiana
}

\author{
Torsten Bullmann ${ }^{\#}$ and Paul A. Stevenson*
}

Institute for Biology II, University of Leipzig, Talstraße 59, 04103, Leipzig, Germany

\begin{abstract}
An antiserum against the nitric oxide (NO) synthetase labelled varicosities surrounding circadian pacemaker cells ("basal retinal neurons", BRNs) in the eye of the marine mollusc Bulla gouldiana. These profiles appear to arise from extrinsic neurons with axons entering the eye via the optic nerve and are distinct from FMRFamide containing profiles, which represent the only efferent optic fibres in Bulla. In intact, dark-adapted eyes, the NO-donor SNAP (S-nitroso$\mathrm{N}$-acetylpenicillamine) had no obvious effect on BRN activity recorded from the optic nerve. However, the light response of these circadian pacemaker neurones was reversibly enhanced by 8-bromo-cGMP, a tissue permeable analogue of cyclic guanosine monophosphate, and reduced by L-NAME ( $\mathrm{N}^{\omega}$-nitro-L-arginine methyl ester), a specific but irreversible inhibitor of NO synthesis. Furthermore, isolated BRNs in primary cell culture responded to the NO-donor SNAP with an elevated intracellular calcium concentration as measured by fluorescent calcium imaging using fura-2. This effect was blocked in the presence of the calcium chelator ethylene glycol tetra acetic acid (EGTA), and mimicked by application of the phosphodiesterase blocker isobutylmethylxanthine (IBMX). We propose that NO released from neurons entering the eyes, modulates the light responsiveness of the circadian pacemaker cells in Bulla by activating cGMP-gated calcium channels.
\end{abstract}

\section{INTRODUCTION}

Evolution has witnessed that several types of light sensitive organs emerge, though in all cases they seem to serve two basic functions, visual perception and the mediation of Zeitgeber information to the circadian pacemaker. The marine opisthobranch mollusc Bulla gouldiana is now an established animal model in circadian biology (review [1]). The eyes of this gastropod contain a population of approximately 100 circadian pacemaker neurones at the base of the retina, so-called basal retinal neurons (BRNs) [2]. The BRNs in each eye are electrically coupled to each other, and their concerted activity produces a circadian rhythm of autogenous compound action potentials during the subjective day that are propagated through the optic nerve to the central nervous system [2]. Isolated BRNs still produce a circadian rhythm in vitro [3] and their activity rhythm in vivo is influenced by incident illumination and by efferent fibres from the brain $[1,5,9]$.

The input pathway for the Zeitgeber light has been thoroughly investigated (review [4]). BRNs are depolarised by illumination and by experimentally elevated extracellular potassium ions [5], whereby both stimuli produce similar phase-shifts in the circadian rhythm [6]. Light or depolarisation induced phase shifts required for extracellular calcium, and are blocked by calcium channel antagonists [6, 7]. Furthermore, depolarisation of the BRNs causes an influx of calcium ions and a robust elevation of intracellular calcium

\footnotetext{
*Address correspondence to this author at the Institute for Biology II, University of Leipzig, Talstraße 59, 04103, Leipzig, Germany;

E-mail: stevenson@rz.uni-leipzig.de

"Present address: University of Leipzig, Paul Flechsig Institute for Brain Research, Department of Molecular and Cellular Mechanisms of Neurodegeneration, Jahnallee 59, 04109 Leipzig, Germany
}

[8]. Thus, calcium plays a central role in phase shifting the ocular circadian pacemaker in molluses [4].

The spiking activity of ocular circadian pacemaker cells is modulated by efferent input in Bulla and in the related Aplysia [9]. Such efferent control is thought to ensure interocular coupling of the pacemakers $[10,11]$, modify the length and amplitude of circadian oscillations [12], and modulate light induced phase shifts [13-15]. However, knowledge of the involved efferent neurotransmitter systems and the underlying cellular mechanisms is limited. The axons of the BRNs in Bulla project via the brain to the contralateral eye [16] and immunocytochemistry, suggest that these cells contain glutamate [17], which is released as an excitatory transmitter for synchronizing inter-ocular pacemaker activity [11]. Efferent fibres immunoreactive for the tetraneuropeptide FMRFamide project through the optic nerve to arborize in the eyes' neuropil of Aplysia, but not Bulla [9, 18], where it suppresses ongoing compound action potentials [9] and modulates light induced phase shifts in both Bulla and Aplysia [19] by acting on potassium currents [20]. In Aplysia, efferent serotonergic fibres that enter and arborize in the eye [21] may act to modulate light's phase shifting effects on the ocular pacemakers [14, 22]. However, this system seems to be absent in Bulla [17]. Beyond these findings, and the observation that octopamine and dopamine occur within the connective tissue encapsulating the eye in Bulla [17], little is known about the involvement of other transmitters in the efferent control of circadian activity in molluscs.

An important signalling molecule in the vertebrate retina is the gas nitric oxide (NO; [23]). In mammals, $\mathrm{NO}$ is also believed to entrain the circadian rhythms generated by the hypothalamic suprachiasmatic nucleus (SCN) clock by acting via a cyclic guanosine monophosphate (cGMP) signal transduction pathway $[24,25]$. NO is now also an estab- 
lished signalling molecule in the nervous systems of invertebrates (reviews [26-29]). Putative NO-releasing neurones have now been identified in numerous molluscs, including Bulla and Aplysia, using both NADPH-d histochemistry and specific antibodies to detect the enzyme NO-synthetase (NOS; [30, 31]; review [32]). Most of the effects of NO are exerted via the activation of soluble guanylyl cyclase and the production of cGMP (review [33]), and evidence suggests that the same applies to molluscs [34-37].

Despite the accumulated knowledge of NO-signalling in molluscs, there is only sparse information on its role in the molluscan visual system and circadian control. NOS has been detected in the optic nerve of Aplysia by NADPHdiaphorase histochemistry [30] and by immunocytochemistry in the retina of the Cephalopod Sepia [38]. In Aplysia, a membrane permeable analogue of cGMP (8Br-cGMP) is reported to phase-shift the ocular circadian pacemaker in the same way as light [39]. In the related Bulla, however, $8 \mathrm{Br}-$ cGMP was not found to produce phase shifts [40]. Apart from this we know only of a meeting abstract reporting that NO mediates the circadian rhythm in photoreceptor sensitivity in Bulla [41]. Here, we now present an evidence suggesting that nitric oxide (NO) is an efferent neuromodulator in the eye of Bulla, that acts via cGMP to enhance the light response of the ocular circadian pacemaker cells by elevating intracellular calcium. A preliminary account of some of the findings reported here has been published elsewhere in short form [42].

\section{MATERIALS AND METHODS}

\section{Experimental Animals}

Adult marine molluscs Bulla gouldiana were obtained from a commercial supplier (Marinus Inc. Long Beach, CA) and maintained in artificial seawater tanks $\left(15.1-15.3^{\circ} \mathrm{C}\right.$, light/dark cycle: 12/12 hours) at Leipzig University for at least 7 days prior to experiments. All experimental procedures are in accord with animal welfare regulations in Germany.

\section{Immunohistochemistry}

The basic procedures employed for detecting bound antisera in sections of paraffin wax embedded tissue were published elsewhere [17]. Briefly, animals were immobilised by injecting isotonic $\mathrm{MgCl}_{2}(10 \mathrm{ml}, 374 \mathrm{mM})$ after which the head ganglia and both eyes were excised within 1 minute. Tissue was passed rapidly through iced artificial seawater, pinned out and immersion fixed for 2 hours at room temperature in paraformaldehyde (4\%) in phosphate buffer $(\mathrm{pH} 7.4)$ supplemented with sucrose to obtain isotonic conditions (1000 mOsm). Tissues were subsequently dehydrated in an ascending ethyl alcohol series, passed through xylene and embedded in paraffin. Serial sagittal sections $(10 \mu \mathrm{m})$ were cut with a rotary microtome (Jung Biocut, Leica, Nussloch, Germany) and mounted on poly-D-lysine coated slides $(0.4$ $\mathrm{mg} / \mathrm{ml}$ ). After removing paraffin in xylene ( 2 changes, each 5 minutes), sections were rehydrated in a descending alcohol series, washed in buffer ( $0.1 \mathrm{M}$ Tris- $\mathrm{HCl}, \mathrm{pH}$ 7.6) containing $0.3 \%$ hydrogen peroxide to block endogenous peroxidase activity (10 minutes) and then fresh buffer (10 minutes). Hereafter all sections were washed for 15 minutes in buffer containing 0.1\% Triton X-100 (Sigma, Steinheim, Germany,
"Tris-HCl-Tx") and then incubated first in normal goat serum (Dako, Hamburg, Germany, 1:10 in Tris-HCl-Tx, 30 minutes) followed by incubation in primary antiserum (in Tris-HCl-Tx with 1\% normal goat serum, 15-18 hours, $20^{\circ} \mathrm{C}$ ). Bound antibody was detected by the avidin-biotin technique using a commercially available kit (Vectastain, Vector, Burlingame, CA, USA), with adherence to recommended dilution and incubation times and employing diaminobenzidine (DAB, $0.02 \%$ in buffer, Polyscience, St. Goar, Germany) with hydrogen peroxide $(0.001 \%)$ as chromogen. As an alternative, bound primary antibody was detected using Cy3-conjugated goat-anti-rabbit antibody (Dianova, Hamburg, Germany) diluted 1:200 in Tris-HCl-Tx. Finally, sections were washed in Tris- $\mathrm{HCl}$, dehydrated in an ascending alcohol series, cleared in xylene and mounted under cover slips in either Entellan (Merck, Darmstadt, Germany) for light-, or Fluoromount (Serva) for fluorescent- microscopy.

\section{Antibodies and Controls}

An established rabbit polyclonal antiserum ("universal" nitric oxide synthetase, anti-NOS, Affinity Bioreagents) was employed to detect putative nitric oxide producing nerve cells and neuropils in cerebral ganglia and the eye. This antibody was raised in rabbit using the peptide DQKRYHEDIFG and affinity purified using the same peptide. The peptide comprises amino acid residues 1113-1122 of murine NOS, with an added N-terminal aspartyl residue, and is highly conserved in all animal NOS. In molluscs, this antibody is now well established, having been shown to recognise NOS by western blot analysis and in the tissues of several different species (e.g., [43-46]). We used this serum at the recommended dilution of 1:200.

Neurones and neuropils containing the molluscan tetrapeptide FMRFamide family were localised using a polyclonal rabbit antiserum originally obtained from Dr. E. Weber, Portland, USA which detects peptides with the terminal peptide sequence arginine-phenylalanine (RF) amide ("RFamide-like peptide"; cf. [47] for details). We used this serum as recommended diluted 1:4000.

The resemblance in the staining pattern of Bulla retina and cerebral ganglia has been reported in an independent study [9]. The tissue staining patterns obtained with the NOS and FMRFamide antisera used here and elsewhere [48] are mutually exclusive, so that cross-reactivity between the two can be excluded. For all antisera tested omission of the primary antiserum and/or secondary antiserum resulted in negative staining in the eye and brain of Bulla.

\section{Image Acquisition and Reproduction}

The photomicrographs for Figs. (1A-D) were taken using a slow-scan 12-bit CCD camera (Sensicam, PCO, Kelheim, Germany) mounted to a compound microscope (DM RBE, Leica, Wetzlar, Germany) equipped with a 20x/0.50 PH2 objective (Leica) using automatic exposure and colour/brightness compensation. The photographs for Figs. (1EF) were obtained with a TCS confocal microscope (Leica) equipped with a 20x/0.50 PH2 objective (Leica). Images were saved on a hard disc without compression in tiff file format. Afterward they were scaled, trimmed, arranged for final figures and converted to 300 dpi 8 bit colour images 


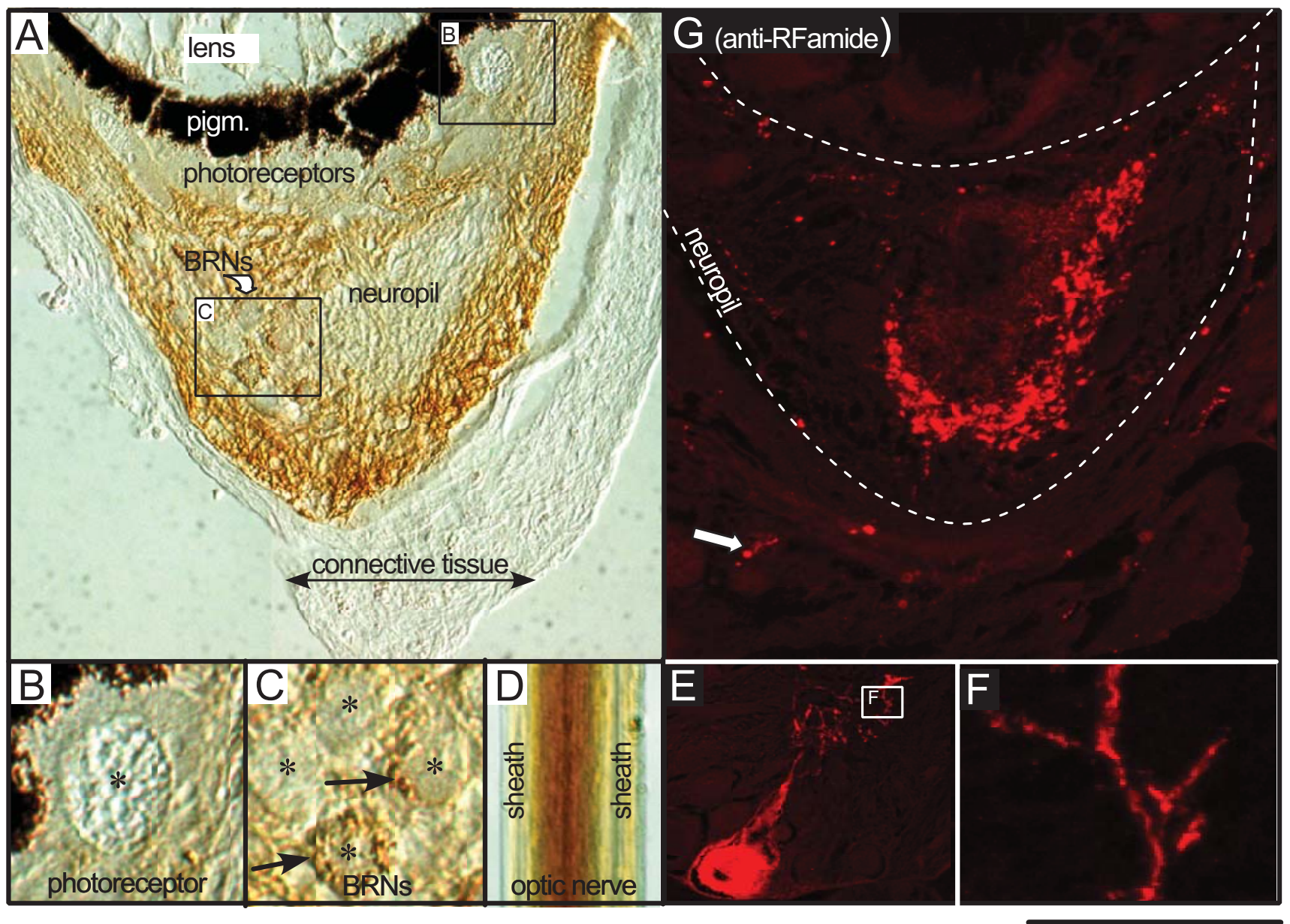

Fig. (1). NOS Photomicrographs of paraffin sections showing NOS-like immunoreactivity in the Bulla eye (A-D) and brain (E, F) compared to RFamide-like immunoreactivity $(\mathbf{G})$. A. Overview of the eye showing the lens, photo-pigment layer, (pigm.) photoreceptor cell-layer, the eye neuropil with NOS-like immunoreactive label (brown) and its encapsulating connective tissue sheath (double-headed arrow; boxes outline a photoreceptor cell and 4 BRNs shown in B respectively C). B. Detail of an unlabelled photoreceptor cell (* nucleus). C. Detail of 4 unlabelled BRNs $(*)$ of which 2 are covered with labelled varicosities (arrows). D. Optic nerve. Note only the core, and not the sheath is labelled. E. An NOS-like immunoreactive soma in the brain (box outlines detail shown in F). F. Detail of branches from the neurone shown in E. G. RFamide-like immunoreactive label (red) in the eye, which is concentrated in regions showing sparse NOS-like immunoreactivity in A (dashed line outlines the neuropil, arrow indicates labelling in the sheath). Bound antiserum was visualised in A-D using DAB as chromogen and Nomarski optics and in E-G using a fluorescent (cy3) secondary antibody and confocal microscopy. Calibration bar: A, D, G 100 $\mu \mathrm{m} ; \mathbf{B}, \mathbf{C}, \mathbf{D}, \mathbf{F} 40 \mu \mathrm{m} ; \mathrm{E} 400 \mu \mathrm{m}$.

using standard software (Canvas, version X, Daneba Systems, Inc. Miami, USA). Beyond this, no further image processing was undertaken.

\section{Extracellular Recordings}

The concerted activity of the electrically coupled circadian pacemaker neurones in Bulla (BRNs) was recorded extracellularly from the optic nerve of intact eyes as compound action potential (CAPs). Snails were taken during their subjective day (CT 10-11), immobilised by injection of isotonic magnesium chloride solution and the brain with attached eyes excised and placed in artificial seawater (ASW). The brain was hemi-sectioned by cutting the cerebral and pedal commissures and the two brain halves transferred to a custom built Teflon recording chamber having three small pools. Each eye was lifted into a separate adjacent pool filled with $100 \mu \mathrm{ASW}$, while the attached brain-half remained in the large pool filled with $500 \mu \mathrm{l}$ ASW. Vaseline served to electrically isolate the eye from its respective brain-half
(Fig. 2). Four silver wire electrodes placed adjacent to each eye and brain-halves were connected to separate differential AC amplifiers (Biopulse unit, ADI Instruments; gain 1000, 1 $\mathrm{kHz}$ high pass, $10 \mathrm{~Hz}$ low pass), which fed into an analogue digital converter (PowerLab, AD-Instruments, $10 \mathrm{kHz}$ sampling frequency/channel) operating with an Apple-Macintosh computer (Cupertino, CA, USA) installed with analysis software (Chart 4, AD-Instruments). An output facility of the PowerLab provided an appropriate signal to illuminate a LED connected to an optic fibre ending $5 \mathrm{~mm}$ equidistant from both eyes.

Each eye's responses to 1 minute light pulses interposed by 15 minute long dark periods was monitored continuously for several hours. Each eye's bathing solution was exchanged manually with a pipette within less than 15 seconds under ambient lighting just after each light pulse. In most experiments the responses to 3 changes of ASW were recorded before applying a drug dissolved in ASW to one eye (test) 


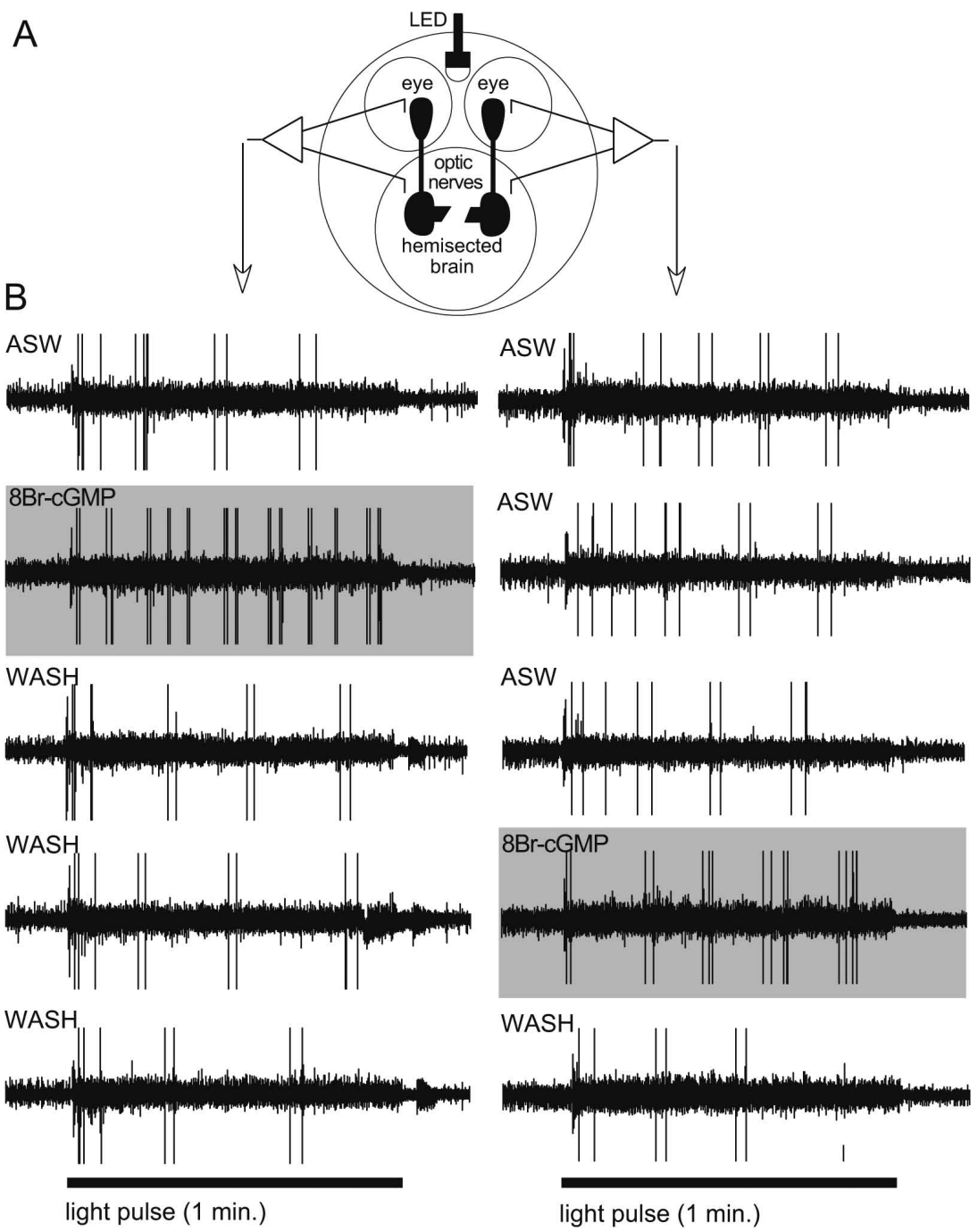

Fig. (2). Enhanced light response of BRNs in an intact, dark adapted, eye preparation following bath application of 8-Br-cGMP. A. Schema of the setup for extracellular recordings of the left and right optic nerves following brief illumination of the eyes with a light emitting diode (LED). B. Simultaneous records from the left and right eye nerves showing bursts of compound action potentials of the BRNs in response to $1 \mathrm{~min}$. light pulses. Consecutive trials, each $15 \mathrm{~min}$ apart, are shown from top to bottom, during which each separate eye is bathed first in artificial seawater (ASW), then in 8-Br-cGMP (100 $\mu \mathrm{M}$, shaded background) followed by washing in artificial seawater (WASH). Compare with Fig. (3).

and ASW to the other (control). These experiments were carried out at room temperature $\left(20-22^{\circ} \mathrm{C}\right)$.

\section{Primary Cell Culture}

Enzymatic dissociation of excised eyes was performed as previously described [3]. The culture medium was prepared from Leibovitz L15 medium [49] and additional salts [50]: $500 \mathrm{ml}$ Leibovitz L15 medium (Sigma) were supplemented with (in g): $7.680 \mathrm{NaCl}, 0.716 \mathrm{CaCl}_{2} \cdot 2 \mathrm{H}_{2} 0,0.147 \mathrm{KCl}$, $1.576 \mathrm{MgSO}_{2} \cdot 7 \mathrm{H} 20,2.644 \mathrm{MgCl}_{2} \cdot 6 \mathrm{H} 20$ (p.a., Fluka), $0.084 \mathrm{NaHCO}_{3}, 3.575$ HEPES, 0.050 L-Glutamine, 3.000 DGlucose (all cell culture tested, Sigma), $\mathrm{pH} 7.8$ adjusted with $10 \mathrm{~N} \mathrm{NaOH}$ (Titrisol, Merck). Medium was sterile filtered and stored at $4{ }^{\circ} \mathrm{C}$. Poly-D-lysine coated cover slips were prepared with $10 \mathrm{mg}$ Poly-D-Lysine (hydrobromide, mol. wt. over 300,000, Sigma) in $50 \mathrm{ml}$ sterile borate buffer (in $\mathrm{g}$ : $0.858 \mathrm{BH}_{3} \mathrm{O}_{3}, 0.682 \mathrm{~B}_{4} \mathrm{Na}_{2} \mathrm{O}_{7} \cdot 10 \mathrm{H} 2 \mathrm{O}$ ).

Animals were immobilised by injecting isotonic $\mathrm{MgCl}_{2}$ $(10 \mathrm{ml}, 374 \mathrm{mM})$, placed on ice, and the eyes dissected out and passed through ASW. The basal retina was carefully dissected from isolated eyes and incubated for 1 hour at $32^{\circ} \mathrm{C}$ in cell culture medium containing $1 \mathrm{mg} / \mathrm{ml}$ Protease VIII (Sigma). Cells were mechanically dispersed in a small drop of cell culture medium on a poly-D-lysine coated cover slip in sterile plastic Petri dish. After 10 minutes the cells became attached to the cover slip and the Petri dish was filled with cell culture medium containing 5-10\% haemolymph.

Cell cultures where maintained in a fridge controlled by a custom-built temperature regulator at $14.5-15.5^{\circ} \mathrm{C}$ in constant darkness and were used on day in vitro (DIV) 2 and 3.

\section{Solutions}

Artificial seawater (ASW) [5] contained (in $\mathrm{mM}$ ): 395 $\mathrm{NaCl}, 10 \mathrm{KCl}, 10 \mathrm{CaCl}_{2}, 50 \mathrm{MgCl}_{2}, 28 \mathrm{Na}_{2} \mathrm{SO}_{4}, 30 \mathrm{HEPES}$ at a $\mathrm{pH}$ of 7.8. In low calcium artificial seawater (EGTAASW) $5 \mathrm{mM}$ calcium was buffered with $10 \mathrm{mM}$ Ethylenebis(oxyethylenenitrilo)tetraacetic acid tetrasodium salt 
(EGTA) to obtain a free calcium concentration of $1,3 \mu \mathrm{M}$. Artificial seawater with elevated potassium [5] contained 50 instead of $10 \mathrm{mM} \mathrm{KCl}$ and $40 \mathrm{mM}$ less $\mathrm{NaCl}$. All chemicals were obtained from Sigma.

\section{Calcium Imaging}

Fura-2 acetoxymethyl ester (Fura-2 AM, Molecular Probes) was used to measure the intracellular concentration of free calcium ions in BRNs as described in detail elsewhere [8]. Briefly, $50 \mu \mathrm{g}$ Fura-2 AM was diluted in $50 \mu \mathrm{l}$ DMSO and vortexed, $10 \mu \mathrm{l}$ of $20 \%$ Pluronic (Molecular Probes) in DMSO was then added and the mixture vortexed again. Aliquots of $10 \mu \mathrm{l}$ were used immediately or stored at $20^{\circ} \mathrm{C}$. The loading solution was made by diluting one aliquot in $1.5 \mathrm{ml} \mathrm{ASW}$ and had a final concentration of $5.6 \mu \mathrm{M}$ fura2 AM. Cells attached to the cover slips were washed with ASW, incubated with loading solution for 30-45 $\mathrm{min}$ at $32^{\circ} \mathrm{C}$, washed with ASW and allowed to recover for $10 \mathrm{~min}-$ utes in fresh plain cell culture medium at $14.5-15.5{ }^{\circ} \mathrm{C}$. Cover slips where then mounted on a custom-built recording chamber mounted on an inverted microscope.

Two $20 \mathrm{~ms}$ light pulses of $340 \mathrm{~nm}$ and $380 \mathrm{~nm}$ were delivered every 4-6 s by a monochromator and the emission was recorded with a photomultiplier tube (Till Photonics, Munich, Germany). The data were digitized and recorded using a Macintosh computer and appropriate software (XChart, Heka, Lambrecht, Germany). Fluorescence ratio was calculated after subtraction of background fluorescence.

The fluorescence measurement equipment was calibrated using a standard protocol [8]. Calibration solution was made using a calibration buffer kit (Molecular Probes) in artificial internal solution containing in mM: $360 \mathrm{KCl}, 5 \mathrm{MgCl}_{2}, 20$ MOPS, pH 7.3 (all from Sigma). Fura-2 potassium salt (Sigma) was diluted to a concentration of $50 \mathrm{mM}$ in water, stored at $4^{\circ} \mathrm{C}$ and was used in a final concentration of 50 $\mu \mathrm{M}$. Parameters were $\mathrm{R}_{\min }=0.284, \mathrm{R}_{\max }=2.535$ and $\mathrm{B}=3.837$. The mean dissociation constant $K_{D}$ of Fura-2 was $205 \mathrm{nM}$ $\left(\mathrm{pK}_{\mathrm{D}}=9.688\right.$ (SEM0.068), $\left.\mathrm{N}=4\right)$. The concentration of free calcium ions was calculated from the background subtracted emission ratio by $\left[\mathrm{Ca}^{2+}\right]_{\text {free }}=\mathrm{K}_{\mathrm{D}} \times\left(\mathrm{R}-\mathrm{R}_{\max }\right) /\left(\mathrm{R}_{\min }-\mathrm{R}\right) \times$ $\mathrm{B}$ as described elsewhere [51].

\section{Statistics}

P-values were taken from Student's t-test. The probability level for rejecting the null hypothesis was $p>0.05$. Measurements were described as mean and standard deviations. Graphs were constructed using SigmaPlot (Jandel, San Rafael). Error bars represent standard deviation. Final figures were arranged using standard software (Canvas X, Daneba Systems). Our account is based all together on a critical evaluation of data from 25 eyes taken from 15 individual animals.

\section{RESULTS}

\section{NOS Immunocytochemistry}

Putative NO producing structures in the nervous system of Bulla gouldiana were revealed in paraffin sections of the eye and brain, using a universal antibody directed against nitric oxide synthetase (NOS). Our findings are based on an evaluation of 7 favourable eye preparations (from 5 individuals) and 5 brain preparations. Fig. (1A) shows a section through the neuropil of the eye, in which NOS-like immunoreactive product is labelled brown. The staining appears to correspond to fine fibres and their processes that are
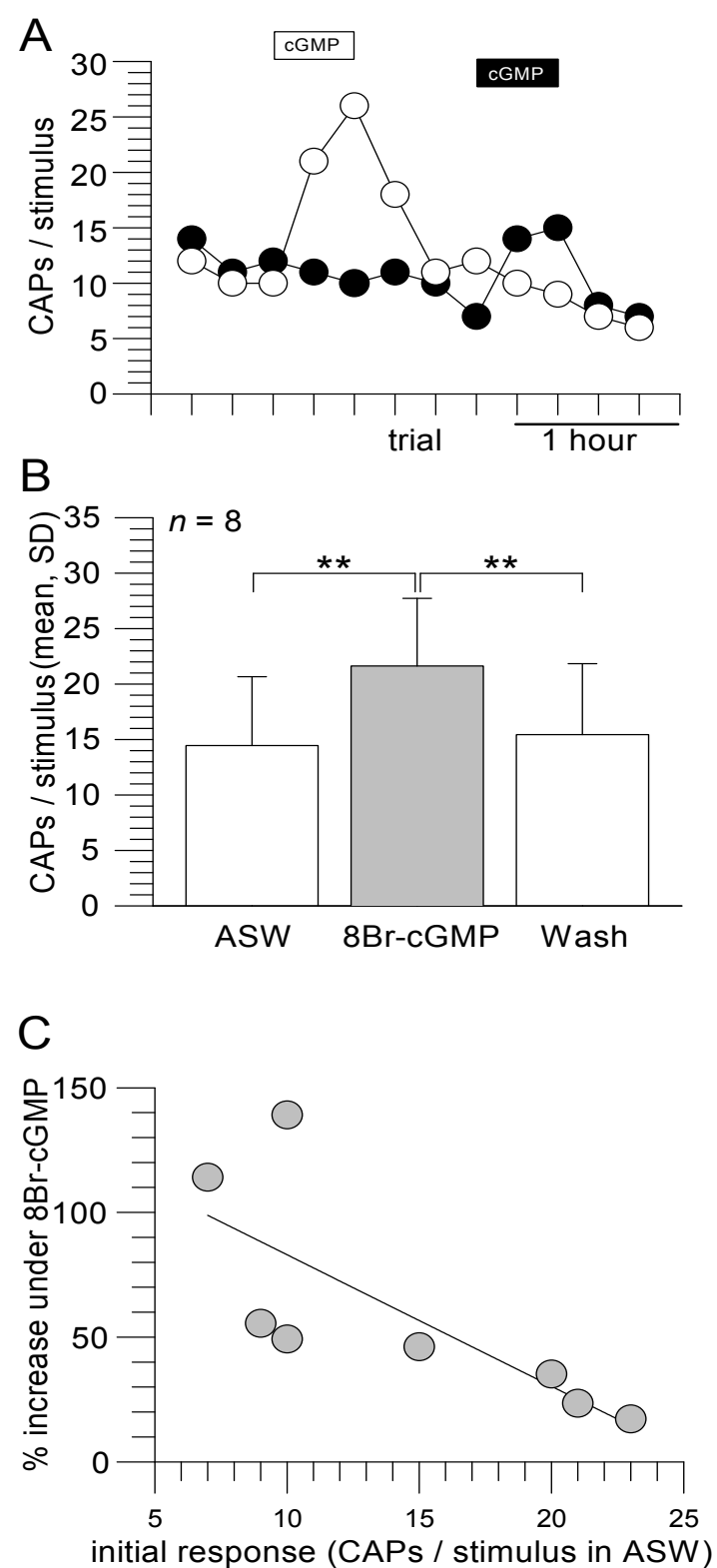

Fig. (3). Evaluation of the effect of 8-Br-cGMP on the light response of BRNs in intact, dark adapted, eye preparations. A. Sequential plot giving the number of compound action potentials recorded during each light pulse (CAPs/stimulus) for consecutive trials recorded simultaneously every 15 mins from the left- (white symbols) and right eye (black symbols) of one individual animal (cf. Fig. 2). Bars indicate periods of incubation in 8-Br-cGMP (100 $\mu \mathrm{M}$, white: left eye, black: right eye). B. Bar chart giving the mean CAPs/stimulus and its standard deviation for 8 individual eyes before (ASW), during (grey bar) and after (WASH) application of 8-Br-cGMP. Significant differences between the means are indicated $\left({ }^{* *}, p<0.01\right.$, Student's paired $t$-test). C. Linear regression analysis indicating that the percentage increase in CAPs per light stimulus under 8-Br-cGMP ( $y$-axis) is inversely correlated to the initial light response in ASW ( $x$-axis) for the eight eyes evaluated (correlation coefficient $-0,75$ ). 
confined within the eye's neuropil. Thus, the connective tissue encapsulating the eye, and the photoreceptor cell bodies (Fig. 1B) below the pigment layer was void of immunoreactive product. Although the cell bodies of the BRNs did not stain, faintly labelled varicose structures were apparent on the surfaces of some of these circadian pacemaker neurones (Fig. 1C). NOS-like immunoreactive staining was also evident in the fibre-containing core of the optic nerve, which connects the eye to the cerebral ganglia. Although the staining here was faint, and no individual fibres could be discerned, the labelling was clear in comparison to the negative staining of the connective tissue enclosing the optic nerve (Fig. 1D). For comparative purposes and as a positive control, Figs. (1E and $\mathbf{F}$ ) show the vivid NOS-immunoreactive labelling of a neurone cell body and its dendritic processes in the Bulla brain. Fig. (1G) shows fluorescent immunocytochemical labelling of the Bulla eye using an antiserum that recognises RFamide-related peptides (e.g., FMRFamide). Similar results were obtained for the 4 eyes taken from 2 animals that we critically evaluated in this respect. Since the distribution of RFamide-like immunoreactivity in the eye (Fig. 1G) clearly differs to that of NOS-like immunoreactivity (Fig. 1A), it is apparent that the antisera directed against these two neuromodulators label different elements in the neuropil.

\section{In Modulation of BRNs in Intact Eyes}

In response to a $1 \mathrm{~min}$. light pulse, a salve of conspicuously large and broad spikes were recorded extracellularly from the optic nerves of dark-adapted eyes during the subjective night (Fig. 2, n=8, cf. Fig. 3). These so-called compound action potentials (CAPs) result from the synchronised spiking of the population of electrically coupled basal retinal neurones BRNs in the eye, which have axons that project to the brain and contralateral eye (cf. [52]). These responses remained stable for several hours. The end of the subjected night was indicated by spontaneous CAP discharges.

Dark adapted, intact eyes, we found no change in the light induced response following bath application of the NOdonor SNAP $(100 \mu \mathrm{M})$ in the four preparations we tested (data not shown). Since we suspect that NO may not readily traverse the thick connective tissue that encapsulates the eye, and/or that SNAP may be fully degraded before doing so, we continued experiments using the membrane permeable and stable analogue of the second messenger cGMP, 8-bromocGMP.

Contrasting the above, 8-bromo-cGMP $(100 \mu \mathrm{M})$ increased the light induced responses in all 8 eyes (from 4 individuals) tested some 15-30 minutes after bath application (Figs. 2 and 3). Example of extracellular recordings from two eyes are shown in Fig. (2B) before, during, and after 8bromo-cGMP application, and the number of CAPs evoked by each light stimulus is plotted in Fig. (3A) for the whole experiment that lasted 3 hours. Subsequent washing in ASW reversed the effect in all cases (Figs. 2B and $\mathbf{3 A}, \mathbf{B}$ ). In the mean, the number of light evoked CAPs was significantly greater (approximately 50\%) in the presence of 8-bromocGMP $(p<0.01$, students paired t-test, $n=8$, Fig. 3B). The magnitude of the effect varied from eye to eye, and we suspect that this may reflect differences in endogenous cGMP levels. Supporting this idea, the net effect of 8-bromo-cGMP
$(100 \mu \mathrm{M})$ was negatively correlated to the initial light response in ASW (Fig. 3C, $y=136.4-3.4 x$, coefficient of linear correlation -0.75).

Further support for endogenous control of the light sensitivity of BRNs by a NO/cGMP pathway was gained using LNAME, a highly specific irreversible inhibitor of NO synthesis. Due to the dependency of the cGMP effect on the eyes initial light response (Fig. 3C), we opted to test the effects of L-NAME on eye preparations that produced an average or above average number of CAPs/stimulus (Fig. 4; hence the larger mean response in $\mathrm{ASW}, \mathrm{n}=5$ eyes from 3
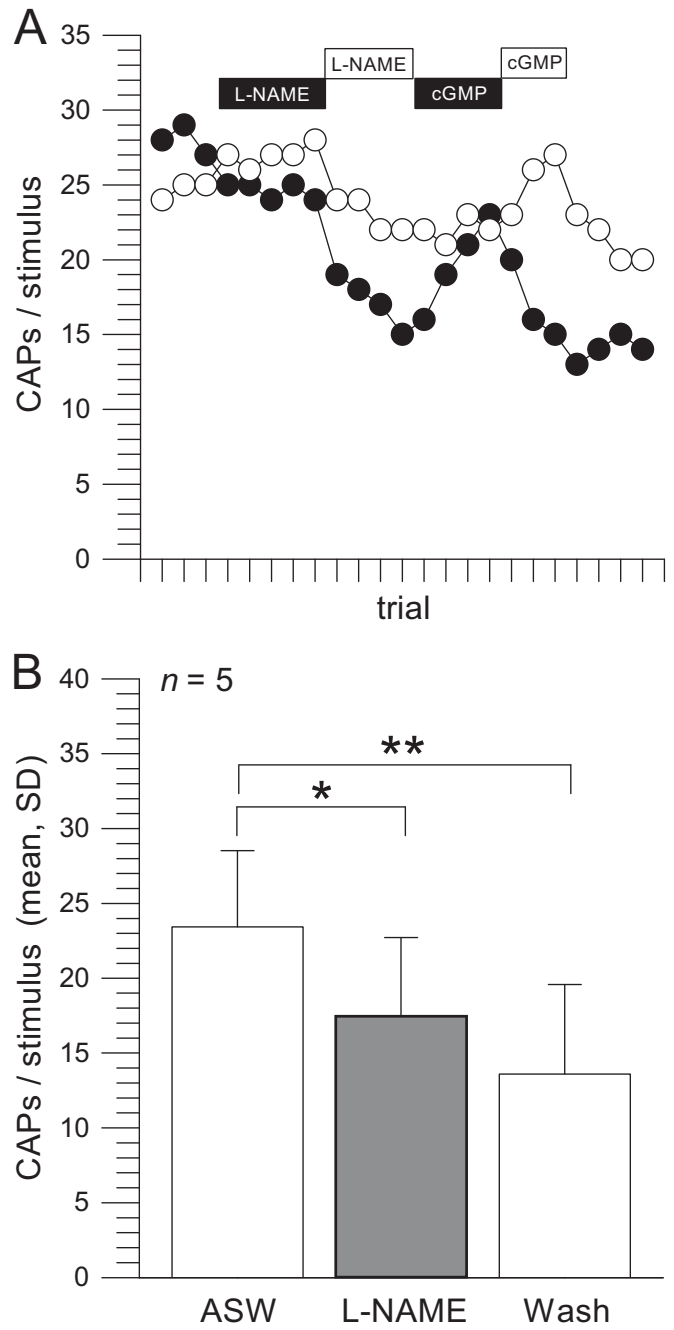

Fig. (4). Depressed light response of BRNs in intact, dark adapted eye preparations following bath application of the irreversible inhibitor or neuronal NOS inhibitor L-NAME $(100 \mu \mathrm{M})$. A. Sequential plot giving the number of CAPs during each light stimulus for consecutive trials recorded simultaneously every $15 \mathrm{mins}$ from the left- (white symbols) and right eye (black symbols) of one individual animal. Bars indicate incubation periods in L-NAME and 8-BrcGMP (white: left eye, black: right eye). Although the effect of LNAME cannot be washed out, the enhanced light responses recorded during application of 8-Br-cGMP (cGMP) testifies the viability of the preparation. B. Bar chart giving the mean $\mathrm{CAP} /$ stimulus and its standard deviation for 5 individual eyes before (ASW), during (grey bar) and after (WASH) application of LNAME. Significant differences between the means are indicated $(*, * * p<0.05,<0.01$ respectively, Student's paired $t$-test). 
individuals). One experiment is depicted in Fig. (4A), which plots the number of CAPs for each light stimulus for two eyes over a period of approximately 6 hours. For both eyes, the light response is diminished in the presence of L-NAME $(100 \mu \mathrm{M})$. As expected, this effect was not washed out in ASW, since the action of L-NAME is irreversible. However, subsequent application of 8-bromo-cGMP $(100 \mu \mathrm{M})$ increased the light response in both eyes, which verified that the responsiveness of the BRNs had not deteriorated during the course of the experiment. Altogether, we found that the light-responsiveness of the BRNs was reduced by some 26 $\%$ after bath application of L-NAME in the 5 individual eyes tested (Fig. 4B, differences between mean CAPs/stimulus significant, Student's paired t-test, $\mathrm{p}<0.05$ ).
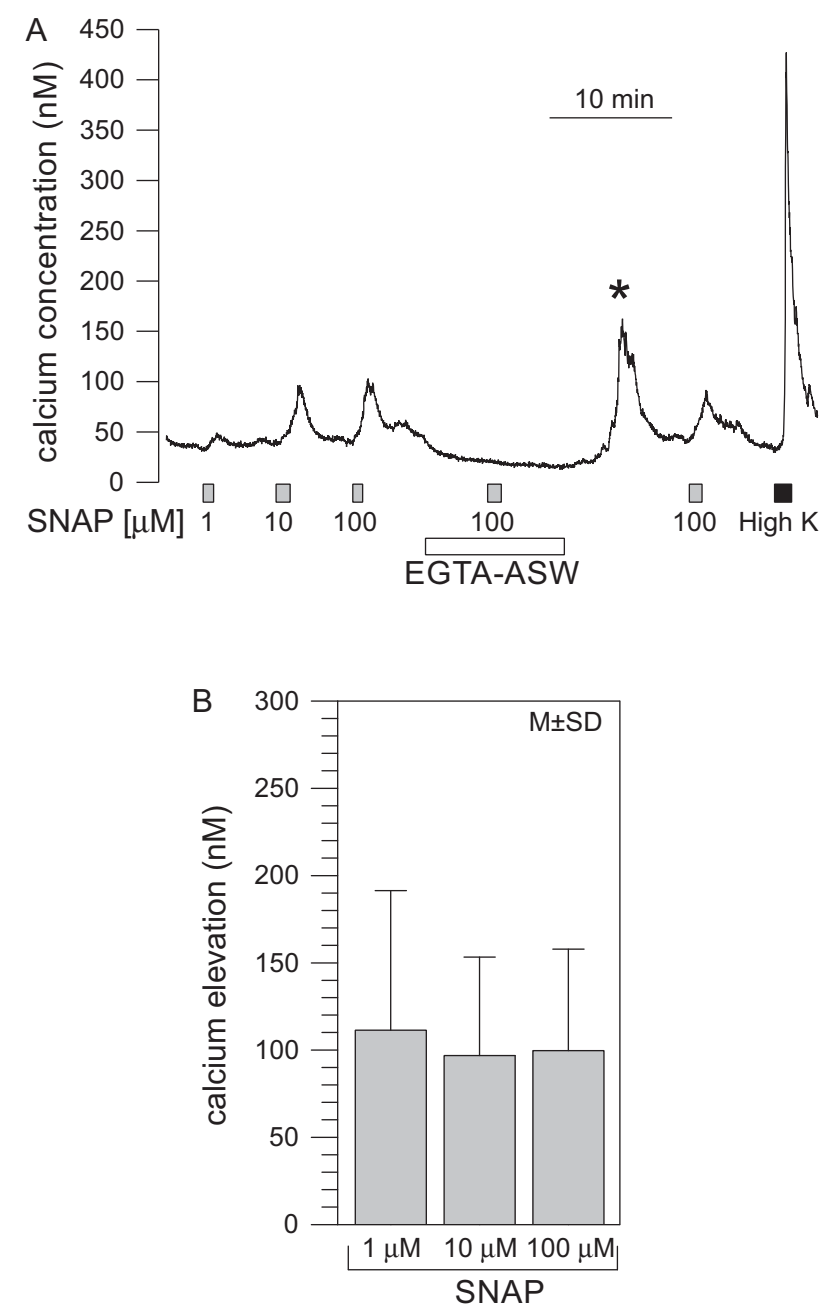

Fig. (5). In vitro optical recording of intracellular $\mathrm{Ca}^{2+}$ concentration in isolated somata of BRNs in primary cell culture. A. Original recording from a single $\mathrm{BRN}$ showing the increased $\mathrm{Ca}^{2+}$ signal following application of the NO-donor SNAP in ASW (grey bars: 1,10 and $100 \mu \mathrm{M}$ ), which is prohibited in the presence of the calcium chelator EGTA (white bar; * note that the elevated calcium signal after washing is due to rebound calcium flux). This cell's calcium-response to depolarisation by high extracellular $\mathrm{K}^{+}$concentration is shown to the far right (high $\mathrm{K}$ ). B. Bar chart giving the mean change in intracellular $\mathrm{Ca}^{2+}$ concentration, and its standard deviation, resulting from application of SNAP (grey bars, $n=5$ ). Note we found no clear dependency of the mean response on the concentration of SNAP in the micro-molar range for the 5 cells tested.

\section{Modulation of Isolated BRNs in Primary Cell Culture}

Isolated BRNs in primary cell culture still express a circadian activity rhythm [3]. In the intact eye this rhythm is phase-shifted by light via a calcium dependant mechanism [53]. We therefore investigated the influence of the NOdonor molecules on the intracellular calcium concentration of isolated BRNs using fura-2.

Bath application of the NOS-donor SNAP caused a fast transient elevation of the intracellular concentration of free calcium in the cell bodies of single isolated BRNs. An example recording is depicted in Fig. (5A). In this cell the least effective SNAP concentration was $1 \mu \mathrm{M}$, which produced a just discernable increase in intracellular calcium concentration of approximately $15 \mathrm{nM}$ above baseline (35 nM). Subsequent application of $10 \mu \mathrm{M}$ SNAP produced a greater, 60 $\mathrm{nM}$, increase, which was in the same order as the maximum increase in intracellular calcium which we recorded in this cell with $100 \mu \mathrm{M}$ SNAP $(64 \mathrm{nM})$. This compares to a 390 $\mathrm{nM}$ increase in calcium observed in this cell following bath application of ASW with high potassium. All cells recorded showed qualitatively the same response to SNAP, although the net effect varied considerably from cell to cell. For the 5 cells critically evaluated (taken from one eye), we found no clear dependency of the mean calcium elevation on the concentration of SNAP applied (Fig. 5B, grey bars). The less specific NO-donor sodium nitroprusside was found to have similar, but inconsistent effects depending on the former decomposition of this compound by red light (data not shown).

The response to $100 \mu \mathrm{M}$ SNAP was abolished in the presence of the calcium chelator EGTA in all 3 cells critically tested (Fig. 5A; note the elevated calcium signal after washing is due to rebound calcium flux). This indicates that the effect of SNAP is due to an influx of extracellular calcium, possibly via cGMP-activated channels. Supporting this, preliminary experiments $(n=2 B R N s)$ revealed that application of the broad band phosphodiesterase inhibitor IBMX, which prohibits breakdown of endogenous cGMP, resulted in a pronounced elevation of intracellular calcium concentration $(>200 \mathrm{nM})$.

\section{DISCUSSION}

Our data from immunocytochemistry of eye-sections of Bulla, together with in situ extracellular electrical recordings, and in vitro optical measurements of intracellular calcium of ocular pacemaker neurones, provide the first evidence that the gas nitric oxide (NO) functions as an endogenous neuromodulator of the circadian clock in a mollusc.

Using immunocytochemical techniques, we detected the enzyme NOS, which is used exclusively for NO production, in the eye neuropil and optic nerve. Whereas mammals possess 3 different NOS isomers, only one has been unequivocally identified in invertebrates, though molluscs are suspected as having two [28]. In the absence of specific antimollusc NOS, antisera directed against mammalian neuronal-NOS have been used to localise putative NOproducing cells in several gastropods other than Bulla, including Helix aspersa [54], Lymnaea stagnalis [45], Aplysia californica, Pleurobranchaea californica, Tritonia diomedea [46], Melibe leonina [55], Ilyanassa obsoleta [56]. In most 
studies of marine invertebrates, the same structures revealed by neural-NOS immunocytochemistry are also detected by NAPDH-diaphorase histochemistry (review [29]), though there are notable exceptions in molluscs $[53,55]$. It has thus been suggested that specific mammalian antisera may not recognise some invertebrate NOS types (cf. [31]). In our study, we employed a "universal" NOS antibody raised against an epitope (DQKRYHEDIFG) conserved in all three mammalian isomers. This serum has been used for localizing NO-producing structures in the nervous tissues of various invertebrates including crustaceans (e.g., [57]) and insects: (Manduca [58]; Drosophila [59]; Locusta [60]), where it detects the same neurones as NADPH-diaphorase histochemistry, but has proved to be superior for revealing efferent fibres [49], and less prone to fixation artefacts (cf. [61]). Pilot experiments with NADPH-diaphorase histochemistry in Bulla produced basically the same staining pattern as NOS-immunocytochemistry (Stevenson, unpublished). However, the blue-black staining product shows poor contrast to the frequently dislodged, black photo pigment, so we favoured immunocytochemistry.

NOS has previously been localised by immunocytochemistry in the retina of the cephalopods Loligo [62] and Sepia [38], but the type and function of the located cells are not known. In our study, NOS-immunocytochemistry revealed no nerve cell bodies within the eye tissues of Bulla. Therefore, fine immunoreactive processes in the optic nerve and eye neuropil surrounding the circadian pacemaker cells (BRNs) must be efferent fibres derived from neurones in the CNS.

Wherever critically investigated, NOS-immunoreactivity or NADPH-diaphorase co-localizes in nervous tissue with a more conventional neurotransmitter, in Aplysia, for example, with myomodulin [30] and histamine [63]. The only conventional neurotransmitters known to date in the eye of Bulla are the peptide FMRFamide $[9,18]$ and the amino acid glutamate [17]. FMRFamide-related peptide occurs in nearly all efferent nitridergic neurones in an insect [49], and in gastropods this peptide has been identified as a substrate source of NOS [64]. However, we rule out the possibility that NOS is co-localised with FMRFamide in the Bulla eye, since the immunocytochemical staining patterns for these two signalling molecules do not coincide. Similarly, NOS does not colocalise with FMRFamide in the CNS of Helix [65]. Glutamate, on the other hand, appears to be the transmitter used in Bulla by the BRNs [17] to mediate bilateral coupling between the two circadian pacemakers [11]. Although the cell bodies of these neurones are frequently surrounded by NOSlike immunoreactive varicosities, they themselves remain unlabelled. Thus, putative NO-releasing terminals are ideally located for modulating the ocular circadian pacemaker cells in Bulla, although the neurons providing this efferent control remain to be identified.

NO can act as a volume signal, spreading tens of micrometers to distance action sites, as in the mammalian cerebellum [66] and mushroom bodies of the insect brain [67]. In a few systems though, close proximity of NOS to its receptor, soluble guanylyl cyclase ( $\mathrm{sGC}$ ) ensures signal specificity, as in the hippocampus, where NO acts as a synapse specific transmitter [68]. Our experiments in Bulla, suggest that the juxtaposition of NOS-immunoreactive varicosities to
BRNs could be of similar functional significance. We propose that local release of $\mathrm{NO}$ stimulates $\mathrm{sGC}$ in BRNs to produce cGMP, which opens cyclic nucleotide gated channels and enables an influx of calcium ions $\left(\mathrm{Ca}^{2+}\right)$, resulting in an enhanced light response (cf. Fig. 6). Supporting this, the NOS-donor SNAP (S-nitroso-N-acetylpenicillamine) caused a fast transient elevation of the intracellular concentration of free calcium in the cell bodies of single isolated BRNs.

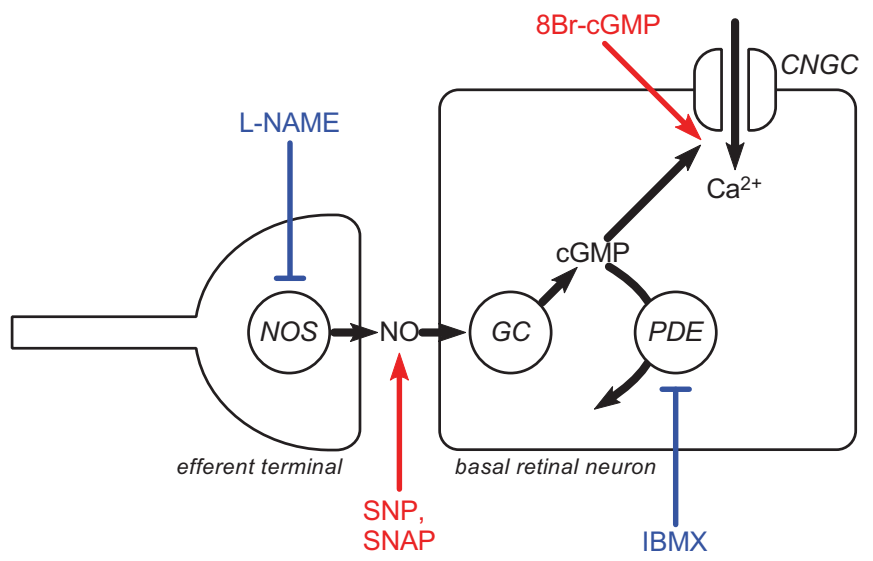

Fig. (6). Schema of the proposed NO-cGMP signalling pathway in the Bulla eye. Efferent neurone fibres containing the enzyme nitric oxide synthetase (NOS) terminate on basal retinal neurones (cf. Fig. 1). Nitric oxide (NO) released by these efferent terminals, or delivered by an NO-donor (SNAP), reaches and enters a basal retinal neuron (BRN) and stimulates guanylate cyclase (GC). This leads to the production of the intracellular second messenger guanine monophosphate (cGMP), which activates cyclic nucleotide gated channels (CNGC) resulting in an influx of calcium ions $\left(\mathrm{Ca}^{2+}\right)$. Elevated calcium could in turn augment the response of the BRN to illumination in vivo. The action of cGMP is terminated by phosphodiesterases (PDE), which are blocked by IBMX.

This must be due to influx of extracellular calcium, since the effect was blocked in the presence of the calcium chelator EGTA. As in vertebrates (review [33]), NO exerts most of its effects in Molluscs via activation of soluble guanylyl cyclase, leading to cGMP formation [34, 35, 36, 37], and cyclic nucleotide-gated ion channels represent one of the three known receptor classes for cGMP [69]. However, cyclic nucleotide independent potentiation of cyclic nucleotide gated cation channels by NO has recently been reported in neurons of the gastropod Pleurobranchia californica [70]. Nonetheless, our data suggest the presence of a NOdependent cGMP-signalling cascade in Bulla BRNs. Firstly, in isolated BRNs, a fast transient increase in intracellular calcium was also caused by the phosphodiesterase blocker IBMX, which can elevate endogenous cGMP by preventing its degradation. This implies a basal activity of guanylyl cyclase in Bulla BRNs, as observed for mammalian retinal guanylyl cyclase [71]. Supporting this, application of the tissue permeable analogue of cyclic guanosine monophosphate, 8-bromo-cGMP to the intact eye reversibly enhanced the light response of the BRNs, recorded as a burst of compound action potentials (CAPs) from the optic nerve. Our observation that the magnitude of this effect was inversely proportional to the initial light responsiveness, also suggests basal activity of the NO/cGMP signalling pathway in BRNs. Finally, although we saw no effect of SNAP on intact eyes, 
L-NAME ( $\mathrm{N}^{\omega}$-nitro-L-arginine methyl ester) a specific but irreversible inhibitor of NO synthesis reduced the response to light, indicating that endogenous NO production may continually regulate light sensitivity of the circadian pacemaker in Bulla.

While our data fit the idea that an NO/cGMP signal cascade increases the light sensitivity of BRNs by activating cyclic nucleotide gated channels, we cannot exclude additional mechanisms. NO may also influence light-evoked CAPs by modulating calcium channels, as shown for lizard cone terminals [72] and salamander rod terminals [73]. In snail feeding neurones, NO modulates voltage dependent Ltype calcium channels, which have also been identified in Bulla BRNs [74], via cGMP induction of channel phosphorylation by protein kinases [37]. NO may modulate the conductance of GAP junctions, as shown in fish retinal neurones, by activating a cGMP-dependent protein kinase [75]. A similar action on the electrically coupled BRNs in Bulla seems unlikely, however, as we observed no obvious effect on the form of their CAPs. Since phototransduction in most invertebrates involves cGMP (review [76]), nitridergic modulation of photoreceptor sensitivity in the Bulla eye, as claimed by Roberts and Willis [41], also seems feasible and has been described in various other animals (molluscs [77]; insects [78, 79]; vertebrates [80]; review [23]). Effects on light adaptation are also possible (vertebrates [72], review: [81]; insects [82]).

We speculate that efferent nitridergic input to the Bulla ocular circadian clock may be involved in phase entrainment. Light pulses synchronize circadian rhythms by inducing phase delays during the early night and phase advances during the late night [6]. In the mammalian suprachiasmatic circadian clock, photic resetting depends on activation of voltage gated calcium channels [83], and a similar mechanism is postulated in Bulla [4, 53]. The BRNs are intrinsically photosensitive and transduce light signals that shift the phase of their pacemaker [84], possibly via an opsin-like photopigment [54]. Furthermore, light induced depolarization leading to a transmembrane calcium influx is essential for light entrainment in both Bulla $[5,6,83,85,86]$ and Aplysia [7]. In mammals, it is hypothesised that the NO/cGMP signalling pathway mediates the phase advancing effects of light on the circadian clock (cf. [87]; review [24]), although there is still no complete consistency in the literature (review [25]). In Aplysia, light increases the levels of cGMP, and 8-bromo-cGMP phase shifts the circadian rhythm in the same direction and magnitude as light [39]. However, the site at which cGMP acts in Aplysia remains to be determined. In Bulla unpublished findings (S. B. Khalsa, cited by [1]) suggest that $8 \mathrm{Br}$-cGMP does not lead to phase shifts, possibly because of limited tissue penetration. The later seems unlikely, since we found that $8 \mathrm{Br}$-cGMP enhances the light response of BRNs in the intact eye. One alternative is that cGMP modulates, rather than mediates, light induced phase shifts, as shown for FMRFamide [19].

NO induced cGMP production may also antagonize the action of cAMP in BRNs. In Bulla, 8-bromo-cAMP applied during the subjective day decreased CAP frequency and produced phase shifts in the circadian rhythm of magnitude and direction depending on the circadian phase [40]. In Aplysia, cAMP is suspected to mediate serotonergic modulation of photic phase shifting $[14,88]$, by activating a hyperpolarizing potassium current, resulting in decreased calcium flux [7]. Serotonin does not occur in the nervous tissues of the Bulla eye [17], but FMRFamide may fulfil a similar role. This tetrapeptide suppresses the light response of basal retinal neurons [9] and blocks light-induced phase changes [19], possibly by attenuating a hyperpolarising, potassium current in the BRNs [20].

Whether FMRFamide influences cAMP in BRNs is not known, although it does not appear to influence calcium flux [20]. Nonetheless, the attractive hypothesis emergent from our study is that the neuromodulator nitric oxide acts as a functional antagonist to FMRFamide in the efferent regulation of light sensitivity of the circadian clock in the eye of Bulla gouldiana. This might contribute to robust entrainment to the natural light dark cycle of day and night even under changeable lighting conditions.

\section{ACKNOWLEDGEMENTS}

We are grateful to Stephan Michel for establishing the primary cell culture, patch clamp techniques and calcium imaging in our laboratory, and for numerous helpful suggestions on this manuscript. We also thank Prof. Klaus Schildberger in whose laboratory this work was carried out, Korinna Schoch for helpful suggestions on anatomical techniques, Elvira Siebert for expert technical assistance and Edgar Buhl for critically reading the manuscript. This work was supported by a grant of the Deutsche Forschungsgemeinschaft awarded to Stephan Michel and Klaus Schildberger, Leipzig University (DFG-Mi 328/2-3).

\section{REFERENCES}

[1] Block GD, Khalsa SB, McMahon DG, Michel S, Guesz M. Biological clocks in the retina: cellular mechanisms of biological timekeeping. Int Rev Cytol 1993;146: 83-144.

[2] Block GD, Wallace SF. Localisation of a circadian pacemaker in the eye of a Mollusc, Bulla. Science 1982; 217(4555): 155-7.

[3] Michel S, Geusz ME, Zaritsky JJ, Block GD. Circadian rhythm in membrane conductance expressed in isolated neurons. Science 1993; 259(5092): 239-41.

[4] Geusz ME, Block GD. Intracellular calcium in the entrainment pathway of molluscan circadian pacemakers. Neurosci Biobehav Rev 1994; 18(4): 555-61.

[5] McMahon DG, Block GD. The Bulla ocular circadian pacemaker. I. Pacemaker neuron membrane potential controls phase through a calcium-dependent mechanism. J Comp Physiol A 1987;161(3): 335-46.

[6] Khalsa SB, Block GD. Calcium channels mediate phase shifts of the Bulla circadian pacemaker. J Comp Physiol A 1988;164(2): 195-206.

[7] Colwell CS, Whitmore D, Michel S, Block GD. Calcium plays a central role in phase shifting the ocular circadian pacemaker of Aplysia. J Comp Physiol A 1994; 175(4): 415-23.

[8] Geusz ME, Michel S, Block GD. Intracellular calcium responses of circadian pacemaker neurons measured with fura-2. Brain Res 1994; 638(1-2): 109-16.

[9] Jacklet JW, Klose M, Goldberg M. FMRF-amide-like immunoreactive efferent fibers and FMRF-amide suppression of pacemaker neurons in eyes of Bulla. J Neurobiol 1987; 18(5): 433-49.

[10] Roberts MH, Block GD. Mutual coupling between the ocular circadian pacemakers of Bulla gouldiana. Science 1983; 221(4605): 87-9.

[11] Ehnert C, Uckermann O, Stevenson PA, Schildberger K, Michel S. Synchronization of circadian pacemaker neurons by chemical and electrical synapses in the marine snail Bulla gouldiana. In: Proceedings of the 28th Göttingen Neurobiology Conference, Göttingen, Germany. Stuttgart, New York: Thieme 2001; p. 770. 
[12] Page TL, Nalovic KG. Properties of mutual coupling between the two circadian pacemakers in the eyes of the mollusc Bulla gouldiana. J Biol Rhythms 1992; 7(3): 213-26.

[13] Corrent G, McAdoo DJ, Eskin A. Serotonin shifts the phase of the circadian rhythm from the Aplysia eye. Science 1978; 202(4371): 977-9.

[14] Colwell CS. Light and serotonin interact in affecting the circadian system of Aplysia. J Comp Physiol A 1990; 167(6): 841-5.

[15] Barnes S, Jacklet JW. Ionic currents of isolated retinal pacemaker neurons: projected daily phase differences and selective enhancement by a phase-shifting neurotransmitter. J Neurophysiol 1997; 77(6): 3075-84.

[16] Lacroix L, Strack S, Olson L, Jacklet JW. Axons of circadian pacemaker neurons in the eye of bulla project to the centralnervous-system and the contralateral eye. Comp Biochem Physiol A 1991; 98: 383-91.

[17] Michel S, Schoch K, Stevenson PA. Amine and amino acid transmitters in the eye of the mollusc Bulla gouldiana: an immunocytochemical study. J Comp Neurol 2000; 425(2): 244-56.

[18] Roberts MH, Moore RY. Localisation of neuropeptides in efferent terminals of the eye in the marine snail, Bulla gouldiana. Cell Tissue Res 1987; 248(1): 67-73.

[19] Colwell CS, Khalsa SB, Block GD. FMRFamide modulates the action of phase shifting agents on the ocular circadian pacemakers of Aplysia and Bulla. J Comp Physiol A 1992; 170(2): 211-5.

[20] Michel S, Ehnert C, Schildberger K. FMRFamide modulates potassium currents in circadian pacemaker neurons of Bulla gouldiana. Neuroscience 2002; 110(1): 181-90.

[21] Takahashi JS, Nelson DE, Eskin A. Immunocytochemical localisation of serotonergic fibers innervating the ocular circadian system of Aplysia. Neuroscience 1989; 28(1): 139-47.

[22] Jacklet JW. Photoresponsiveness of Aplysia eye is modulated by the ocular circadian pacemaker and serotonin. Biol Bull 1991; 180: 284-94.

[23] Cudeiro J, Rivadulla C. Sight and insight--on the physiological role of nitric oxide in the visual system. Trends Neurosci 1999; 22(3): 109-16.

[24] Golombek DA, Agostino PV, Plano SA, Ferreyra GA. Signaling in the mammalian circadian clock: the NO/cGMP pathway. Neurochem Int 2004; 45(6): 929-36.

[25] Morin LP, Allen CN. The circadian visual system, 2005. Brain Res Rev 2006; 51(1): 1-60.

[26] Jacklet JW. Nitric oxide signaling in invertebrates. Invert Neurosci 1997; 3(1): 1-14.

[27] Colasanti M, Venturini G. Nitric oxide in invertebrates. Mol Neurobiol 1998; 17(1-3): 157-74

[28] Moroz LL. Gaseous transmission across time and species. Am Zool 2001; 41: 304-20.

[29] Palumbo A. Nitric oxide in marine invertebrates: A comparative perspective. Comp Biochem Physiol A 2005; 142: 241-8.

[30] Jacklet JW, Gruhn M. Co-localisation of NADPH-diaphorase and myomodulin in synaptic glomeruli of Aplysia. Neuroreport 1994; 5(14): 1841-4

[31] Moroz LL. Localisation of putative nitrergic neurons in peripheral chemosensory areas and the central nervous system of Aplysia californica. J Comp Neurol 2006; 495(1): 10-20.

[32] Moroz LL, Gillette R. From Polyplacophora to Cephalopoda: comparative analysis of nitric oxide signalling in mollusca. Acta Biol Hung 1995; 46(2-4): 169-82.

[33] Krumenacker JS, Hanafy KA, Murad F. Regulation of nitric oxide and soluble guanylyl cyclase. Brain Res Bull 2004; 62(6): 505-15.

[34] Koh HY, Jacklet JW. Nitric oxide stimulates cGMP production and mimics synaptic responses in metacerebral neurons of Aplysia. J Neurosci 1999; 19(10): 3818-26.

[35] Fujie S, Yamamoto T, Murakami J, et al. Nitric oxide synthase and soluble guanylyl cyclase underlying the modulation of electrical oscillations in a central olfactory organ. J Neurobiol 2005; 62(1): 14-30.

[36] Bodnárová M, Martásek P, Moroz LL. Calcium/calmodulin-dependent nitric oxide synthase activity in the CNS of Aplysia californica: biochemical characterization and link to cGMP pathways. J Inorg Biochem 2005; 99(4): 922-8.

[37] Zsombok A, Schrofner S, Hermann A, Kerschbaum HH. A cGMPdependent cascade enhances an L-type-like Ca2+ current in identified snail neurons. Brain Res 2005; 1032(1-2): 70-6.
[38] Di Cosmo A, Di Cristo C, Palumbo A, d'Ischia M, Messenger JB. Nitric oxide synthase (NOS) in the brain of the cephalopod Sepia officinalis. J Comp Neurol 2000; 428(3): 411-27.

[39] Eskin A, Takahashi JS, Zatz M, Block GD. Cyclic guanosine 3':5'monophosphate mimics the effects of light on a circadian pacemaker in the eye of aplysia. J Neurosci 1984; 4(10): 2466-71.

[40] Ralph MR, Khalsa SBS, Block GD. Cyclic-nucleotides and circadian-rhythm generation in Bulla gouldiana. Comp Biochem Physiol A 1992; 101: 813-7.

[41] Roberts MH, Willis JL. The circadian-rhythm in photoreceptor sensitivity recorded from the eye of Bulla gouldiana Is Mediated by Nitric-Oxide. Mol Biol Cell 1995; 6: 2055.

[42] Bullmann T, Schildberger K, Stevenson PA. Nitric oxide as an endogenous modulator of circadian pacemaker cells in the snail Bulla gouldiana. In: Proceedings of the 29th Göttingen Neurobiology Conference, Göttingen, Germany. Stuttgart, New York: Thieme; 2003; p. 772.

[43] Davidson SK, Koropatnick TA, Kossmehl R, Sycuro L McFall-Ngai MJ. NO means 'yes' in the squid-vibrio symbiosis: nitric oxide (NO) during the initial stages of a beneficial association. Cell Microbiol 2004; 6: 1139-51.

[44] Villamil L, Gomez-Leon J, Gomez-Chiarri M. Role of nitric oxide in the defenses of Crassostrea virginica to experimental infection with the protozoan parasite Perkinsus marinus. Dev Comp Immunol 2007; 31: 968-77.

[45] Moroz LL, Winlow W, Turner RW, Bulloch AG, Lukowiak K, Syed NI. Nitric oxide synthase-immunoreactive cells in the CNS and periphery of Lymnaea. Neuroreport 1994; 5(10): 1277-80.

[46] Hurst WJ, Moroz LL, Gillette MU, Gillette R. Nitric oxide synthase imunolabeling in the molluscan CNS and peripheral tissues. Biochem Biophys Res Commun 1999; 262(2): 545-8.

[47] Stevenson PA, Pflüger HJ. Colocalisation of octopamine and FMRFamide related peptide in identified heart projecting (DUM) neurones in the locust revealed by immunocytochemistry. Brain Res 1994; 638(1-2): 117-25.

[48] Bullerjahn A, Mentel T, Pflüger HJ, Stevenson PA. Nitric oxide: a co-modulator of efferent peptidergic neurosecretory cells including a unique octopaminergic neurone innervating locust heart. Cell Tissue Res 2006; 325(2): 345-60.

[49] Leibovitz A. The growth and mainteance of tissue-cell cultures in free gas exchange with the atmosphere. Am J Hyg 1963; 78: 17380 .

[50] Schacher S, Proshansky E. Neurite regeneration by Aplysia neurons in dissociated cell-culture - modulation by Aplysia hemolymph and the presence of the initial axonal segment. J Neurosci 1983; 3(12): 2403-13.

[51] Grynkiewicz G, Poenie M, Tsien RY. A new generation of Ca2+ indicators with greatly improved fluorescence properties. J Biol Chem 1985; 260(6): 3440-50.

[52] Block GD, Geusz ME, Khalsa SBS, Michel S. A clockwork Bulla cellular study of a model circadian system. Semin Neurosci 1995; 7: $37-42$.

[53] Geusz ME, Foster RG, DeGrip WJ, Block GD. Opsin-like immunoreactivity in the circadian pacemaker neurons and photoreceptors of the eye of the opisthobranch mollusc Bulla gouldiana. Cell Tissue Res 1997; 287(1): 203-10.

[54] Cooke IRC, Edwards SL, Anderson CR. The distribution of NADPH diaphorase activity and immunoreactivity to nitric oxide synthetase in the nervous system of the pulmonate mollusc Helix aspersa. Cell Tissue Res 1994; 277: 565-72.

[55] Newcomb JM, Watson WH 3rd. Identifiable nitrergic neurons in the central nervous system of the nudibranch Melibe leonina localised with NADPH-diaphorase histochemistry and nitric oxide synthase immunoreactivity. J Comp Neurol 2001; 437(1): 70-8.

[56] Thavaradhara K, Leise EM. Localisation of nitric oxide synthaselike immunoreactivity in the developing nervous system of the snail Ilyanassa obsoleta. J Neurocytol 2001; 30(6): 449-56.

[57] Scholz NL, de Vente J, Truman JW, Graubard K. Neural network partitioning by NO and cGMP. J Neurosci 2001; 21(5): 1610-8.

[58] Nighorn A, Gibson NJ, Rivers DM, Hildebrand JG, Morton DB. The nitric oxide-cGMP pathway may mediate communication between sensory afferents and projection neurons in the antennal lobe of Manduca sexta. J Neurosci 1998; 18(18): 7244-55.

[59] Gibbs SM, Truman JW. Nitric oxide and cyclic GMP regulate retinal patterning in the optic lobe of Drosophila. Neuron 1998; 20(1): 83-93. 
[60] Bullerjahn A, Pflüger HJ. The distribution of putative nitric oxide releasing neurones in the locust abdominal nervous system: a comparison of NADPHd histochemistry and NOS-immunocytochemistry. Zoology (Jena) 2003; 106(1): 3-17.

[61] Ott SR, Burrows M. Nitric oxide synthase in the thoracic ganglia of the locust: distribution in the neuropiles and morphology of neurones. J Comp Neurol 1998; 395(2): 217-30.

[62] Kimura T, Shouno O, Matsumoto G. NADPH-diaphorase containing cells and fibers in the central nervous system of squid, Loligo bleekeri keferstein. Life Sci 1997; 61(24): 2375-81.

[63] Jacklet JW. Nitric oxide is used as an orthograde cotransmitter at identified histaminergic synapses. J Neurophysiol 1995; 74(2): 891-5.

[64] Roszer T, Kiss-Tóth E, Petkó M, Szentmiklósi AJ, Bánfalvi G. Phe-met-arg-phe (FMRF)-amide is a substrate source of NO synthase in the gastropod nervous system. Cell Tissue Res 2006; 325(3): 567-75.

[65] Roszer T, Jenei Z, Gáll T, et al. A possible stimulatory effect of FMRFamide on neural nitric oxide production in the central nervous system of Helix lucorum L. Brain Behav Evol 2004; 63(1): 2333.

[66] Jacoby S, Sims RE, Hartell NA. Nitric oxide is required for the induction and heterosynaptic spread of long-term potentiation in rat cerebellar slices. J Physiol 2001; 535(Pt 3): 825-39.

[67] Ott SR, Philippides A, Elphick MR, O'Shea M. Enhanced fidelity of diffusive nitric oxide signalling by the spatial segregation of source and target neurones in the memory centre of an insect brain. Eur J Neurosci 2007; 25(1): 181-90.

[68] Burette A, Zabel U, Weinberg RJ, Schmidt HH, Valtschanoff JG. Synaptic localisation of nitric oxide synthase and soluble guanylyl cyclase in the hippocampus. J Neurosci 2002; 22(20): 8961-70.

[69] Biel M, Sautter A, Ludwig A, Hofmann F, Zong X. Cyclic nucleotide-gated channels--mediators of NO:cGMP-regulated processes. Naunyn Schmiedebergs Arch Pharmacol 1998; 358(1): 140-4.

[70] Hatcher NG, Sudlow LC, Moroz LL, Gillette R. Nitric oxide potentiates cAMP-gated cation current in feeding neurons of Pleurobranchaea californica independent of cAMP and cGMP signaling pathways. J Neurophysiol 2006; 95(5): 3219-27.

[71] Shyjan AW, de Sauvage FJ, Gillett NA, Goeddel DV, Lowe DG. Molecular cloning of a retina-specific membrane guanylyl cyclase. Neuron 1992; 9(4): 727-37.

[72] Savchenko A, Barnes S, Kramer RH. Cyclic-nucleotide-gated channels mediate synaptic feedback by nitric oxide. Nature 1997; 390(6661): 694-8.

[73] Kurenni DE, Thurlow GA, Turner RW, Moroz LL, Sharkey KA, Barnes S. Nitric oxide synthase in tiger salamander retina. J Comp Neurol 1995; 361(3): 525-36.
[74] Michel S, Kahlsa SB, Block GD. Calcium current in circadian pacemaker neurons of the marine snail Bulla. Eur J Neurosci 1994; 7: 145 .

[75] Lu C, McMahon DG. Modulation of hybrid bass retinal gap junctional channel gating by nitric oxide. J Physiol 1997; 499(Pt 3): 689-99.

[76] O'Day PM, Bacigalupo J, Vergara C, Haab JE. Current issues in invertebrate phototransduction. Second messengers and ion conductances. Mol Neurobiol 1997; 15(1): 41-63.

[77] del Pilar Gomez M, Nasi E. Activation of light-dependent K+ channels in ciliary invertebrate photoreceptors involves cGMP but not the IP3/Ca2+ cascade. Neuron 1995; 15(3): 607-18.

[78] Bacigalupo J, Bautista DM, Brink DL, Hetzer JF, O'Day PM. Cyclic-GMP enhances light-induced excitation and induces membrane currents in Drosophila retinal photoreceptors. J Neurosci 1995; 15(11): 7196-200.

[79] Schmachtenberg O, Bicker G. Nitric oxide and cyclic GMP modulate photoreceptor cell responses in the visual system of the locust J Exp Biol 1999; 202(1): 13-20.

[80] Kawa F, Sterling P. cGMP modulates spike responses of retinal ganglion cells via a cGMP-gated current. Vis Neurosci 2002; 19(3): 373-80.

[81] Djamgoz MB, Sekaran S, Angotzi AR, et al. Light-adaptive role of nitric oxide in the outer retina of lower vertebrates: a brief review. Philos Trans R Soc Lond B Biol Sci 2000; 355(1401): 1199-203.

[82] Jones IW, Elphick MR. Dark-dependent soluble guanylyl cyclase activity in locust photoreceptor cells. Proc R Soc Lond B 1999; 266(1417): 413-9.

[83] Kim DY, Choi HJ, Kim JS, et al. Voltage-gated calcium channels play crucial roles in the glutamate-induced phase shifts of the rat suprachiasmatic circadian clock. Eur J Neurosci 2005; 21(5): 121522.

[84] Block GD, McMahon DG, Wallace SF, Friesen WO. Cellular analysis of the Bulla ocular circadian pacemaker system 1. A model for retinal organization. J Comp Physiol A 1984; 155: 36578.

[85] Khalsa SB, Block GD. Calcium in phase control of the Bulla circadian pacemaker. Brain Res 1990; 506(1): 40-5.

[86] Ralph MR, Block GD. Circadian and light-induced conductance changes in putative pacemaker cells of Bulla gouldiana. J Comp Physiol A 1990; 166(5): 589-95.

[87] Ding JM, Chen D, Weber ET, Faiman LE, Rea MA, Gillette MU. Resetting the biological clock: mediation of nocturnal circadian shifts by glutamate and NO. Science 1994; 266(5191): 1713-7.

[88] Corrent G, Eskin A. Transmitterlike action of serotonin in phase shifting a rhythm from the Aplysia eye. Am J Physiol 1982; 242(3): R333-8.

(c) Bullmann and Stevenson; Licensee Bentham Open.

This is an open access article licensed under the terms of the Creative Commons Attribution Non-Commercial License (http://creativecommons.org/licenses/by-nc/3.0/) which permits unrestricted, non-commercial use, distribution and reproduction in any medium, provided the work is properly cited. 